\title{
MINERÍA, REGALÍAS Y POLÍTICA TRIBUTARIA
}

\author{
Dr. Victor Torres Cuzcano*
}

El sector minero (léase minería metálica) aporta alrededor de $6 \%$ del PBI nacional, contribuye con $50 \%$ de las divisas que ingresan al país por concepto de exportaciones y explica $15 \%$ de la Inversión Extranjera Directa registrada en el país. Asimismo, en América Latina la minería peruana ocupa el segundo lugar en la producción de cobre (quinto en el mundo), y el primer lugar en la producción de oro y zinc (sexto y tercero en el mundo, respectivamente). Por tanto, es indiscutible su importante participación en las cifras macroeconómicas del país.

En el aspecto tributario, sin embargo, el panorama cambia de manera significativa. Según información publicada por la Superintendencia Nacional de Administración TributariaSUNAT $^{2}$, la participación del sector en la recaudación del IGV (cuenta propia) no superaría el $2 \%$, y en la recaudación del Impuesto a la Renta (tercera categoría), sería de aproximadamente $12 \%$. Si sólo tomamos en cuenta estos dos impuestos, que son los que en estricto reflejan la contribución tributaria de las empresas mineras, su participación relativa en el total de los tributos internos recaudados por la SUNAT (excluidas las contribuciones sociales) sería de aproximadamente 3\% del total. ¿Qué razones explican este resultado?

\section{El marco tributario del sector}

Si bien la actividad minera, al igual que cualquier otro sector económico, está formalmente sujeta al marco tributario vigente en el país, ella ha gozado de beneficios tributarios que, sumados al hecho de tratarse de una actividad orientada fundamentalmente a la exportación, contribuyen a explicar la poca participación del sector en la generación de ingresos tributarios para el Estado.

En el caso del Impuesto General a las Ventas - IGV, éste grava las ventas internas en el país mas no así las exportaciones, lo cual implica que la mayor parte de las ventas del sector minero (exportaciones) no está afecta al IGV. Por tanto, su débito fiscal es mínimo; en cambio, sus compras -al estar gravadas con el impuesto- sí generan un elevado crédito fiscal. De lo cual resulta que el impuesto determinado de las empresas mineras (débito menos crédito) registra elevados saldos negativos, que en la jerga tributaria se conocen como «saldos a favor del exportador». Es decir, no sólo no se generan pagos del IGV, sino que además la empresa minera puede utilizar dichos saldos para pagar el Impuesto a la Renta, o -en su defectopuede solicitar su devolución. Ello explica la mínima participación del sector en la

* Docente de la Unidad de Postgrado de la Facultad de Ciencias Contables.

1 Decreto Supremo N. ${ }^{\circ}$ 014-92-EM, publicado el 04/06/92. 
recaudación del IGV. Además el Régimen de Recuperación Anticipada del IGV les permite recuperar, durante la etapa preoperativa (durante la cual no se generan débitos fiscales), el crédito fiscal generado en sus importaciones y adquisiciones locales.

En lo referente al Impuesto a la Renta de tercera categoría, la poca participación del sector en la recaudación del mismo se explica por determinados beneficios tributarios, además del uso de los «saldos a favor del exportador» arriba mencionados. Veamos:

Reinversión de utilidades: La Ley General de Minería de $1992^{1}$ permitía a las empresas mineras reinvertir hasta el $80 \%$ de sus utilidades y deducir el monto reinvertido de la base imponible del Impuesto a la Renta. Según información del Ministerio de Energía y Minas, fueron empresas de la grande y mediana minería las que se acogieron a este beneficio ${ }^{2}$, lo que constituye un indicador de la magnitud del efecto negativo que esta medida tuvo en la recaudación del Impuesto a la Renta. Durante 1994-1999, en el sector minero se reinvirtieron utilidades libres del Impuesto a la Renta por aproximadamente US\$ 950 millones ${ }^{3}$; por tanto, el impuesto no pagado durante dicho período habría ascendido a S/. 130 millones anuales. $\mathrm{Si}$ bien este beneficio quedó sin efecto en septiembre del $2000^{4}$, las empresas que contaban con programas de inversión ya aprobados lo han seguido utilizando hasta el ejercicio 2003.

Doble depreciación: Entre 1994 y 1998, estuvo vigente en el país el beneficio tributario que facultaba a una empresa adquiriente, de cualquier sector económico, a depreciar los activos que le fueran transferidos en el marco de una reorganización de empresas (fusión o división), activos que previamente podían haber sido revaluados por la empresa transferente $o$ absorbida ${ }^{5}$. La ley permitía aplicar como gasto deducible contra el pago del Impuesto a la Renta la depreciación correspondiente al valor revaluado de activos. Por tanto, mientras mayor fuese el valor revaluado, mayor sería la depreciación, y por ende mayor serían los gastos deducibles aplicados contra el Impuesto a la Renta de tercera categoría, disminuyendo así el impuesto a pagar. Sobre la base de una muestra representativa compuesta por 153 empresas, la SUNAT $^{6}$ estima una pérdida en la recaudación del Impuesto a la Renta, debido a este beneficio, ascendente a S/. 339 millones hasta el 20017. En el caso del sector minería e hidrocarburos, siete empresas revaluaron activos que representan $18.6 \%$ del total revaluado ${ }^{8}$, y la pérdida en la recaudación asciende a $S / .12 .3$ millones. Este monto, sin embargo, no resulta significativo frente a la pérdida de $S / .190$ millones que se concentra en cuatro empresas del sector energía eléctrica.

2 Refinería de Zinc Cajamarquilla S.A., Southern Perú, Cía. Minera Milpo, Minsur S.A., Volcan Cía. Minera, Cía. Minera Caravelí, Cía. Minera Atacocha, entre otras.

3 Según declaraciones del Viceministro de Minas, Juan Mendoza Marsano; diario Gestión, Lima, miércoles 10 de mayo del 2000.

4 Ley N. ${ }^{\circ} 27343$, publicada el 05/09/00.

5 Ley N. ${ }^{\circ} 26283$, publicada el 13/01/94 y su Reglamento, D.S. N. ${ }^{\circ} 120-94-E F$, publicado el 21/09/94.

6 SUNAT (2002b).

7 Este monto incluye el arrastre de pérdidas generadas al cierre del ejercicio 1998 y que están pendientes de compensación (hasta el año 2001).

8 Las 153 empresas revaluaron activos por un valor de S/.7,089 millones, cifra que representa la tercera parte del activo fijo total de dicha muestra para el ejercicio 1999. 
Sin embargo, varias empresas han seguido gozando de este beneficio a pesar de su derogación a fines de $1998^{\circ}$, pues consideran que al haber coincidido en el tiempo la vigencia de este beneficio con la firma de un Convenio de Estabilidad Jurídica con el Estado peruano, el referido beneficio quedaba «congelado" ${ }^{10}$. Según la SUNAT ${ }^{11}$, debido a los referidos convenios, el beneficio de la doble depreciación ha seguido operando sobre cuatro empresas, tres del sector electricidad y una del sector minero, las cuales concentran la mayor parte de los activos revaluados entre 1994 y 1998. La pérdida por concepto del beneficio de la doble depreciación aplicado por estas cuatro empresas con posterioridad a 1998 asciende a S/. 1,135 millones ${ }^{12}$.

\section{Política tributaria, regalías e inversión minera}

Valgan verdades, este tratamiento tributario promocional que se otorga al sector minero no es exclusividad del Perú. La mayor parte de países mineros recurre a estas políticas con el fin de atraer el capital extranjero que asegure la elevada inversión y el largo período de maduración que involucra todo proyecto minero.

A inicios de los 90, el Perú cambió sustancialmente su marco regulatorio y tributario con el objetivo explícito de atraer inversión extranjera en exploración y explotación minera. La fuerte inversión en exploración minera

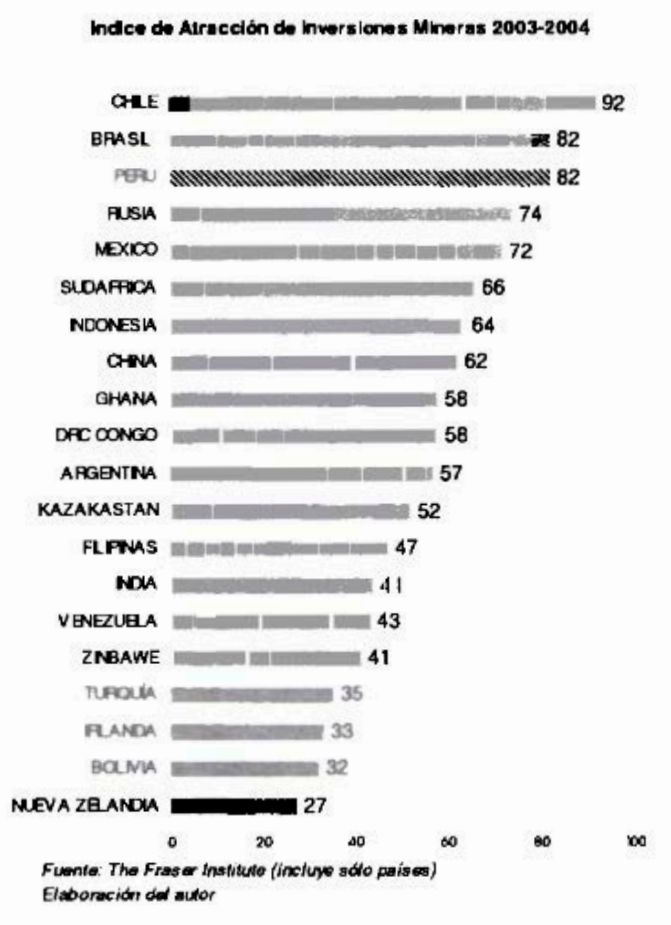

registrada durante los 90 evidenció lo acertado de dicha política. Ello, sumado a la relativa estabilidad económica y política que ha ganado el país en los últimos años, han hecho de la minería peruana una de las más atractivas del mundo, y así lo demuestran estudios internacionales sobre el tema.

Así, según la Encuesta Anual de Compañias Mineras 2003/2004 que el Instituto Fraser de Canadá aplica entre las principales empresas mineras del mundo ${ }^{13}$, el índice del potencial de politica gubernamental ${ }^{14}$ ubica al Perú en quinto lugar en un ranking de 20 países; el indice de potencial minero ${ }^{15}$ lo ubica en segundo lugar (superando a Chile, que ocupa el tercer lugar), en tanto que el indice de

9 Dicho monto resulta de sumar el Impuesto a la Renta incurrido en el período 1999-2001 (S/.373 millones) más los montos pendientes por aplicar, tanto por depreciación pendiente como por pérdida compensable (S/. 732 millones).

10 Ver al respecto The Fraser Institute (2004).

11 El índice mide los efectos de las políticas gubernamentales en las inversiones en exploración, incluyendo tributación, regulaciones ambientales, reclamos de tierra de los nativos, etc.

12 El índice evalúa los atractivos de una región basado en las percepciones geológicas de las compañías.

${ }_{13}$ El índice de potencial minero tiene un peso de $60 \%$ y el índice potencial de políticas, $40 \%$. 
atracción de inversiones mineras, que pondera los dos precedentes ${ }^{16}$, ubica al Perú en tercer lugar en el ranking por países, compartiendo el mismo puntaje con Brasil (segundo lugar) y sólo después de Chile.

Por otro lado, sobre la base de un estudio que utiliza el modelo desarrollado por el Institute for Global Resources Policy and Management de la Colorado School of Mines, James Otto estima la tasa de retorno del inversionista extranjero en 23 países del mundo según distintos escenarios tributarios ${ }^{17}$, llegando a la conclusión que el régimen tributario vigente en la minería peruana es uno de los más competitivos del mundo.

Por tanto, la política tributaria en el sector minero debería adecuarse a este nuevo contexto favorable al país, estableciendo un equilibrio entre la justa ganancia de las empresas mineras y la necesidad de que todos paguen sus impuestos, como debería ocurrir en un país con altos índices de pobreza como el Perú. En tal sentido, podría resultar pertinente reevaluar la política tributaria minera, sin exagerar los efectos que ello pueda tener en el capital extranjero. El principio de seguridad jurídica, por ejemplo, que con justa razón reclaman los inversionistas mineros, está muy bien cubierto por los Convenios de Estabilidad Jurídica que éstos pueden firmar con el Estado peruano.
Sobre este y otros aspectos de la política tributaria minera en el Perú, resulta interesante sopesar las recomendaciones de James Otto que a continuación resumimos (formuladas en THE WORLD BANK, 2003), las mismas que fueron cuantificadas por dicho autor a fin de evitar un impacto negativo en las tasas de retorno de los potenciales inversionistas:

1) Continuar con los acuerdos de estabilidad jurídica, pero en los futuros convenios debería agregarse hasta cinco puntos porcentuales adicionales a la tasa del Impuesto a la Renta. La legislación vigente no contempla punto adicional alguno .

2) Continuar con la depreciación acelerada de $20 \%$ anual en cinco años para las maquinarias y equipos, $y$ extender este beneficio a las edificaciones (5\% actualmente).

3) Extender el límite de arrastre de pérdidas de cuatro a 10 años, o no imponer límite alguno, como lo hace la mayor parte de países mineros.

4) Continuar aceptando como gasto deducible de la renta imponible los gastos en infraestructura que constituya servicio público, mejorando su operatividad y extendiendo el beneficio a las actividades de formación y educación de las comunidades locales.

14 El referido modelo define tipos hipotéticos de minas de cobre y oro, a las que se aplica diferentes regímenes tributarios. Ver al respecto la contribución de James OTTO (Capítulo VIII) en THE WORLD BANK (2003).

15 Desde su publicación a fines de 1991, el marco regulatorio de los referidos Convenios prácticamente no había sido modificado. En septiembre del 2000 (Ley $N^{\circ} 27342$ ) se produjeron algunos ajustes: el Impuesto a la Renta se estabilizaría añadiendo a la tasa vigente dos puntos porcentuales, se elevaron los montos mínimos de Inversión, los convenios dejaban de tener vigencia en el caso de reorganización de empresas. Sin embargo, este último aspecto fue eliminado en diciembre de ese mismo año (Ley $\mathrm{N}^{\circ} 27391$ ) y los dos puntos adicionales del Impuesto a la Renta fueron eliminados en agosto del 2001 (Ley $\mathrm{N}^{\circ} 27514$ ). 
5) Persistir en la eliminación del beneficio de la reinversión de utilidades, pues su aplicación no es de práctica común entre los países que recepcionan inversión extranjera en minería.

6) Aplicar regalías razonables sobre la base de los ingresos obtenidos por las ventas mineras, que no exceda de una tasa de 3\%; medida que debe ir de la mano con la eliminación de los derechos que gravan las importaciones mineras. Al respecto debe precisarse, por un lado, que el Perú y Chile son dos de los pocos países del mundo que no imponen regalías sobre sus recursos mineros. Por otro lado, la legislación vigente permite a las empresas de cualquier sector económico deducir los referidos derechos de importación del pago del Impuesto a la Renta.

7) Revisar el manejo oficial del tema medioambiental, descentralizando su gestión, asegurando el buen diseño y cumplimiento de las regulaciones e integrando en la consulta y el monitoreo medioambiental a las organizaciones locales involucradas, con el apoyo de ONGs.

\section{CONCLUSIONES}

Por supuesto, la contribución de la actividad minera en el desarrollo del país no sólo debe ser medida según su aporte a la recaudación tributaria. Debe tomar en cuenta, también, su importante participación en la generación de divisas, creación de puestos de trabajo, construcción de infraestructura social, efecto multiplicador en actividades económicas laterales o derivadas, entre otros aspectos. Sin embargo, la valoración de dicha contribución debería incluir además los recursos que se pierden o se deterioran de manera irreparable como consecuencia de la actividad minera (los pasivos ambientales, por ejemplo), a efectos de tener una medición más exacta de la misma. Ello permitirá enriquecer nuestra constante preocupación por alcanzar estándares internacionales, incorporando -además de un marco tributario competitivo para la inversión minera- la búsqueda de un desarrollo local, regional y nacional ambientalmente sostenible.

\section{BIBLIOGRAFÍA}

- MINISTERIO DE ENERGÍA Y MINAS (2001). Plan referencial de minería 2000-2009; Lima, MEM, noviembre 2000-julio 2001.

- SUNAT (2002a) Estimación del efecto de los convenios de estabilidad jurídica sobre la recaudación. Lima, SUNAT, setiembre 2002.

- SUNAT (2002b). Estimación del efecto de la mayor depreciación de la revaluación de activos sobre la recaudación. Acuerdos de fusión o división, Ley N. $^{\circ} 26283$ y D.S. $N^{\circ} 120-94-$ $E F$. Lima, SUNAT, octubre 2002.

- THE FRASER INSTITUTE (2004). Annual Survey of Mining Companies 2003/2004, Canadá, http://www.fraserinstitute.ca/ . Martes, 1 de junio 2004.

- THE WORLD BANK (2003). Restoring Fiscal Discipline for Poverty Reduction in Peru. A public expenditure review. Washington, BM-BID, june 2003. 